\title{
The Reading Comprehension Levels of Grade 12 ABM Students: An ESP Design for Basic English Course
}

\author{
Jasmin M. Sumipo \\ Ph. D. Mater Dei College, Tubigon, Bohol, Philippines \\ darleymine1@yahoo.com
}

This study determined the reading comprehension level of grade 12 ABM students of Mater Dei College, Tubigon, Bohol during the school year 2018-2019 with 95 subjects comprising the entire population. Participants were mostly from rural junior high schools of northern part of Bohol.

John's Basic Reading Inventory was individually administered to each student to collect the needed data for this study. The gathered data was used to conceptualize the proposed English for Specific Purposes modules for basic English course, particularly for the senior high school ABM students. Analysis on the data gathered was anchored on the different theories of reading comprehension

The findings of the reading inventory administered to the grade $12 \mathrm{ABM}$ students revealed that their oral and silent reading comprehension levelwas generally on frustration level. This shows that a big percentage of students were not able to analyze the passage correctly. Hence, the students need much assistance from the teacher in analyzing the selection.

The conclusion drawn is that the grade $12 \mathrm{ABM}$ students are deficient in all aspects of reading comprehension. Though they may be slightly proficient in identifying main ideas and recalling facts, but they were generally deficient in making evaluation, drawing out inferences, following sequence, and vocabulary. The study also showed that oral and silent reading comprehension has a positive correlation.

The researcher gave the following recommendations: that an English for Specific Purposes module be developed and used for basic English courses, students who are in instructional and frustration level be given tutorial and remedial teaching activities respectively, and that English teachers use authentic situation in teaching English language in their particular discipline.

Introduction:
In the past, education was seen as a means of acquiring wisdom. The demand of economic life, however, is such that modern education equip students with necessary knowledge and skills for them to be easily employed. This paradigm shift calls for instructional structural reforms in schools to create new types of training that will be of practical significance in terms of their students' future careers.

One of the goals of adding two more years in high school is to prepare the students for their future career. Mater Dei College High School, being one of the biggest schools in Bohol in terms of senior high school students population, is faced with the challenge of producing high school graduates who are not only ready for their next level of education, but who are job ready in the near future.

Having handled English courses for senior high, the researcher had past personal experiences which demonstrated the students' lack of knowledge of specialized lexicon akin to their field. When students were tasked to write some words under correct heading, the teacher was shocked when most students placed items radish and bitter gourd under the heading, "things to wear".

The above-mentioned scenario showed presumably inadequacies in the school's current English curriculum. Moreover, the comments of tertiary teachers on senior high graduates having poor vocabulary skills and being ill equipped in their college courses prodded the researcher to embark on this study.

\section{Theoretical Background}

Comprehension is said to be evidenced by the reader's ability to a) identify the main idea, b.) retain concepts and organize facts, c.) isolate details and recall specific facts, d.) make an inference, and e.) draw conclusion (Giroux and Willistin cited by Laguilles, 1994). Still another indicator of comprehension is the ability of the 
reader to put meaning to unfamiliar vocabulary with or without the aid of contextual clues. For the purposes of this study, the categories set by Giroux and Williston will be used since these are more commonly invoked for secondary students who are expected to have engaged in reading across contest areas. Also these categories are reflected on John's Basic Reading Inventory, the instrument used in this study.

Comprehension is thinking on the highest level. It is a cognitive process. It requires inference, verifying, correcting, and confirming of expectancies about the text. Smith (cited by Barchers, 1997) emphasized a more holistic view that comprehension may be regarded as relating relevant aspects of the worlds around us-written language in the case of reading- to the intentions, knowledge, and expectations already existing in one's head.

In the expressive language modes of speaking and writing, comprehension means understanding the message well enough to compose it clearly. In the receptive language modes of listening and reading, comprehension means interpreting the message accurately enough to understand its meaning (Duffy \&Roehler, 1993.) The various language modes are so inextricably bound making it almost impossible to each one in isolation from the others.

Recently, reading comprehension has been studied in the light of the Schema Theory. According to Sampson et al (2003:133), "This existing information store known as the reader's schema, is an important concept in understanding the process of reading comprehension. "This schema includes single events, situations encountered, things learned, and even sequences of events (Rumelhart, 1984). This schema is used in the interpretation of an event, an object, or a situation in the process of comprehension. Readers comprehend the text when they are able to activate their schema. Anino (1999) concurred when he stated that readers bring to reading the sum of all their prior experiences and expectations about print.

Traditionally, the teaching of English has been for General Purposes which has been named 'TENOR' - the teaching of English for No Obvious Reason, no obvious reason to the learner, that is (Jordan, 1997). The paradigm shift of modern education which stresses on economic demands and fields of specialization calls for teaching of English for the obvious reas on of equipping the students the kind of English which assures immediate employment in their chosen fields.

The influence that the ESP approach has on English teaching cannot be underrated. The fact that every field has its own jargon or specialized words and phrases used in the course of everyday work which the students have to be equipped with if they are to success in their fields underscores the importance of ESP course design.

In discussing ESP exercise typology, Douglas (1984) maintains that the main consideration must be that of authenticity. All ESP work is in essence a simulation of real-life task. Furthermore, Dudley-Evans (1998) enumerates the absolute characteristics of ESP as follows: 1.) ESP is designed to meet specific needs of learners; 2.) ESP makes use of underlying methodology and activities of the discipline it serves, and 3.) ESP is centered on the language appropriate to these activities in terms of grammar, lexis, register, study skills, discourse and genre.

\section{The Problem}

This study attempted to determine the reading skills and comprehension levels of grade 12 ABM students as basis for designing an English for Specific Purposes modules for senior high English subjects.

Specifically, this study aimed to answer the following questions:

1. What is the reading comprehension level of the grade 12 ABM students in both oral and silent reading?

2. What is the reading comprehension level of participants of the study with reference to the following aspects:

1.1 main ideas

1.2 facts

1.3 vocabulary

1.4 inference

1.5 sequence, and

1.6 evaluation?

3. What are the common miscues committed in the student's oral reading?

4. What is the extent to which the miscues affect the participants' comprehension levels?

5. How may an ESP module for senior high core English subjects be designed based on the findings?

Methodology

Descriptive research was utilized in this study. The main data were taken from the reading comprehension inventory administered to grade 12 ABM students of Mater Dei College. Results were analyzed and interpreted by the researcher to come up with the answers to the problems and sub-problems. These findings were made as bases for the ESP course module.

Research Instrument 
In order to pinpoint the specific reading skills which students were weak at, the researcher adopted Jerry John's informal reading inventory. John's basic reading inventory provides an informal assessment of the reading comprehension skills of the students namely, facts, main idea, vocabulary, inferences, sequence and experience or evaluation.

Two sets of standardized reading passages with corresponding questionnaires were used. Each passage contains about 240 words. Both questionnaires were used for oral and silent reading comprehension respectively have ten item questions. There is one time for main idea, inference, sequence, and evaluation. There are four items for facts and two items for vocabulary.

The total score is ten. Those who will get a score of 9-10 fall under independent level; 6-8 are in instructional; 5 or less in frustration. A research subject belongs to the independent level if he could read a book or material without difficulty and does not need assistance from the teacher. He is considered to be instructional if he could read the book but there is a need for some help from the teacher. A subject is considered to be in frustration level when he could barely read and hardly comprehend what he reads.

Results

The oral reading of majority of the students under study was on frustration level. This showed that there is a crucial need to help the students improve their ability to read orally and comprehend what they are reading. Less than $30 \%$ of the subject fall under instructional level or those who need teacher's assistance to comprehend the

Table 1

Oral Reading Comprehension Levels of 12 ABM Students

\begin{tabular}{lll}
\hline Levels & Frequency & Percentage \\
\hline $\begin{array}{l}\text { Independent Level } \\
(9-10)\end{array}$ & 2 & 2.11 \\
$\begin{array}{l}\text { Instructional Level } \\
(6-8)\end{array}$ & 26 & 27.27 \\
$\begin{array}{l}\text { Frustration } \\
(5 \text { or less })\end{array}$ & 67 & 70.53 \\
\hline Total & 95 & 100.00 \\
\hline
\end{tabular}

A great majority of the research subjects considered the reading material difficult as evidenced by how they read orally. This is because the students were used to oral reading activities which focus is correct pronunciation of passage. Only two subjects reached the independent level and were able to work well on the passage. This means that only these students could comfortably cope with the readings required at their present grade level.

Majority of the subjects were likewise categorized as being on frustration level in silent reading. This means that the students urgently needs great assistance to enable them to do well in reading activities. Less than $25 \%$ of the students were classified as instructional. These students have to be assisted to improve their comprehension. Only one subject was able to comprehend well and was classified as independent, the level in which students could cope with the reading activities of their current grade level.

The aspects of vocabulary and sequence were considered by majority of the subjects as the most difficult. These were followed by aspects of inference, fact, and evaluation which the subjects considered as slightly difficult. Identifying the main idea was easiest for research subjects.

The most common significant miscues committed were meaning-changing substitution and grammatical blunders. Majority of the subjects who committed miscues were classified on frustration level. This showed that reading comprehension is affected by miscues incurred while reading orally.

Analys is

When students read orally, teachers have tremendous opportunities to examine how students are interacting with printed materials (Johns, 1986). Table 1 below presents the oral reading comprehension levels based on the number of students who got the items correctly. 
comprehend the reading material presented to them.

Furthermore, the subjects may have no past knowledge about the topic in the reading passage making it difficult for them to process the new information. Readers find it easier to comprehend new information if they have related previous experience. This is supported by Barchers (1998:88) when she said, "Schema theory is building new connections and knowledge on existing experience".

Table.2: Silent Reading Comprehension Levels of 12 ABM Students

\begin{tabular}{lcc}
\hline Levels & Frequency & Percentage \\
\hline $\begin{array}{l}\text { Independent Level } \\
(9-10)\end{array}$ & 1 & 1.05 \\
Instructional Level & 23 & 24.21 \\
$(6-8)$ & 71 & 74.74 \\
$\begin{array}{l}\text { Frustration Level } \\
(5 \text { or less })\end{array}$ & & \\
\hline
\end{tabular}

Total

100. 00

A big percentage of the research subjects had poor comprehension as evidenced by the low scores they got on the test. The unsatisfactory reading achievement can be attributed to several factors. Most of the research subjects were not able to understand the material well because they have no prior knowledge on the topic of the reading passage. Readers comprehend text when they are able to find a configuration of hypotheses (schema) which offers a coherent account for the various aspects of the text (Rummelhart, 1984). This enables the reader to form a framework of known information so they can hook new information into it. Another factor which may have caused the poor reading comprehension is the inability of the students to use the cueing systems in reading. This insight is backed up Smith (1982) when he mentioned, "Readers arrive at meaning by using their knowledge or scriptural information about the topic and by using three basic cueing systems, (1) cue systems with words (graphophones), (2) cue systems within the structure or flow of the language (syntax) and (3) cue systems within the person reading the message (semantics).

With a majority of the research subjects who are categorized under frustration level, it is clear that most of them do not have the mastery to use the three basic cueing systems cited above. La Berge \& Samuels cited by Sampson et. al. 2003, has this to say

Another theory of reading suggests that all reading have a finite or limited amount of attention available to them during reading. This attention can be devoted either to the process of decoding words or to the process of comprehension. If much attention is required to decode words, then less attention is available for comprehending the text.

Table.3: Students'Scores on Different Aspects of Comprehension during Oral Reading

\begin{tabular}{lll}
\hline Aspects of Reading & Total & Percentage \\
\hline Main Idea & 50 & 52.63 \\
Fact & 46.5 & 48.95 \\
Evaluation & 43 & 45.26 \\
Inference & 35 & 36.84 \\
Sequence & 29.5 & 31.05 \\
Vocabulary & 22 & 23.16 \\
\hline
\end{tabular}

Of the six aspects, the subjects are poorest in vocabulary. Many students struggle particularly with words that have different meanings in different contexts. Words that students do not use in their everyday language also cause difficulty. The students' weakness in vocabulary greatly affected their reading comprehension. According to Rummelhart (1988), vocabulary knowledge is fundamental to reading comprehension since a reader cannot understand the meaning of the whole text without knowledge of most of the words. 


\begin{tabular}{lll}
\hline Aspects of Reading & Total & Percentage \\
\hline Main Idea & 50 & 52.63 \\
Fact & 49 & 51.58 \\
Evaluation & 47.5 & 50.00 \\
Inference & 36 & 37.89 \\
Sequence & 30 & 31.58 \\
Vocabulary & 20.5 & 21.58 \\
\hline
\end{tabular}

Overall, the subjects still considered the aspect of main idea as the easiest as this was the area they got the highest scores. Though the percentage is far below the passing rate, locating the main idea proved to be an easier task in comparison with the rest. This is largely due to the fact that the central thought was explicitly stated at the beginning of the reading material.

The subjects scored lowest on the aspect of vocabulary. Students usually find it difficult to give word meaning. They are not well-versed at using context clues to derive the meaning of words. They generally low scores seem to indicate that the subjects have not reached maturity the way effective readers would. It may be concluded that the school and the home failed to provide the stimulation necessary for the students to attain mature reading capability. Moreover, the accessibility of television, computers, and mobile phones has taken the place of reading books.

Common Miscues Committed

Complete accuracy in oral reading is virtually impossible for some reasons. First, students sometimes make wrong predictions. Second, sometimes, they need to reread in order to grasp message that the author wants to convey. Third, since reading is a dynamic interaction between the author and the student, miscues are a natural part of the process itself. Miscues from the printed text can be used to provide insights into the students' reading. For these reasons, the researcher wanted to find out the common miscues; but focused only on significant deviations which affect reading comprehension.

Table.5: Common Miscues Committed during Oral Reading

\begin{tabular}{lcl}
\hline Types of Miscues & Frequency & Percentage \\
\hline Meaning-Changing Word Substitution & 55 & 57.89 \\
Grammatical Difference & 56 & 48.42 \\
Meaning- Changing Omissions & 23 & 24.21 \\
Repetition & 15 & 15.79 \\
Failure to Attempt Unknown Words & 10 & 10.53 \\
Non-word Substitution & 8 & 8.42 \\
\hline
\end{tabular}

The most common miscue is meaning-changing word substitution. It appeared that students usually resorted to word substitution when they encountered difficult worlds while reading. Substituting one word with another word could also be attributed to the fact that students do not know how to pronounce a certain word, so that substitute it with other words. Another reason would be that while reading students failed to see the relationship among words and phrases in the sentences and the passage in its entirety. Though several substitutions were committed, non-meaning changing substitutions, such as changing the article a tothe,were disregarded by the researcher since they do not affect reading comprehension.

Extent to which the Miscues Affect the Reading Comprehension Level 
Table.6: Common Miscues Committed by Students under Instructional and Frustration Levels

\begin{tabular}{|c|c|c|c|c|}
\hline Types of Miscues & Ins. & $\%$ & $\begin{array}{l}\text { Frust. } \\
n=67\end{array}$ & $\%$ \\
\hline Grammatical Difference & 8 & 29.63 & 38 & 56. 72 \\
\hline Meaning- Changing Omissions & 4 & 14.81 & 24 & 35.82 \\
\hline Non-word Substitution & 0 & 0.00 & 8 & 11.94 \\
\hline
\end{tabular}

In contrast to the subjects who are classified as instructional who committed a few errors in the common types of miscues, the subjects who are under frustration level committed a generally higher frequency in all types of miscues during the oral reading. This means that subjects who incurred miscues in oral reading were more likely to commit errors during examinations. Also, this may indicate that the reading comprehension of students is generally affected when they incur significant miscues during oral reading. Dallman et al (1982:166) stated that, "Oral reading, if not done well, can have an undesirable effect on comprehension. The reader can become so conscious of his audience that he will fail to understand what he is reading. Moreover, the number of miscues committed by the subjects may be a gauge of whether subjects find the material difficult or easy as evidenced by a greater number of students under frustration level who committed reading miscues and who scored low in the reading comprehension test.

\section{REFERENCES}

[1] Barchers, S.I. (1998). Teaching reading from process to practice. Wads worth Publishing Co., 1998

[2] Dallman, M. et al. (1982). The teaching of reading, $6^{\text {th }}$ Edition. United Kingdom: CBS College Publishing

[3] Douglas, D. (2000). Assessing language for specific purposes. United Kingdom. Cambridge University Press

[4] Dudley-Evans, T. (1998). Developments in English for specific purposes. United Kingdom. Cambridge University Press

[5] Duffy, G.G., Roehler, L.R. (1993). Improving classroom reading instruction: a decision- making approach $3^{\text {rd }}$ Edition. Mc. Graw-Hill, Inc.

[6] Johns, J.L. (1986). Handbook for remediation of reading difficulties. New Jersey. Prentice-Hall, Inc.
[7] Jordan, R.R. (1997). English for academic purposes: a guide and resource book for teacher. United Kingdom. Cambridge University Press.

[8] Hutchinson, T. \& Waters, A. (1987). English for specific purposes: a learner-centered approach. Cambridge University Press.

[9] Laguilles, T.M. (1994). Curricular implications of extensive reading and writing. Unpublished Master of Arts in English Language Teaching Thesis, University of San Carlos.

[10] Rummelhart, D.E. (1988). Schemata: the building blocks of cognition. New York. International Reading Association, Inc.

[11] Sampson, M.B. et al (2003). Total literacy: reading, writing, and learning, $3^{\text {rd }}$ edition. Canada, Wadsworth, A Thompson Learning, Inc.

[12] Smith, R. (1998). Thoughtful reading. Perfection Forum Co. 